Nigerian Journal of Physiological Sciences 22 (1-2): 109-116 CPhysiological Society of Nigeria, 2007

Available online/abstracted at http://www.biolineinternational.org.br/njps; www.ajol.info/journals.njps; www.cas.org

\title{
ENDOTHELIUM-DEPENDENT AND -INDEPENDENT RELAXATIONS IN AORTIC RINGS OBTAINED FROM HYPERTENSIVE HOODED (AGUTI) RATS.
}

\author{
F. B. O. MOJIMINIYI,* C. N. ANIGBOGU, ${ }^{\dagger}$ O. A. SOFOLA, ${ }^{\dagger}$ S. A. ADIGUN ${ }^{\dagger}$ \\ *Department of Physiology, College of Health Sciences, Usman Danfodio University, Sokoto, \\ Nigeria and Department of Physiology, College of Medicine, University of Lagos, Nigeria. \\ P.M.B. 2254, Sokoto, Nigeria. E-mail: mojiminiyi@yahoo.co.uk Tel: +234-8059538456
}

\begin{abstract}
Summary: Experimental hypertension studies are few in the hooded (Aguti) rat. The present study was designed to investigate the usefulness of this rat strain for experimental hypertension studies and to test the hypothesis that the hypertension may be associated with a diminution of endothelium dependent and independent relaxations. Hypertension was induced in inbred hooded rats $(\mathrm{n}=8$ each) by administering $8 \%$ salt in the diet and /or $100 \mathrm{mg} / \mathrm{kg} /$ day $\mathrm{N}^{\omega}$-nitro-L-arginine-methyl-ester (LNAME) in the drinking water for six and/or four weeks respectively. The rats were anaesthetized using a $25 \%$ urethane and $1 \%$ chloralose mixture given intraperitoneally at a dose of $5 \mathrm{mg} / \mathrm{kg}$. Their blood pressure was measured invasively. Thereafter, relaxations of rat aortic preparations to acetylcholine, histamine and sodium nitroprusside (SNP) were assessed using standard organ bath conditions. $\mathrm{P}<0.05$ was taken as statistically significant. The mean arterial pressure (MAP;mm Hg) rose significantly in all test groups (Salt: 148.3 \pm 4.6 ; L-NAME: 181.7 \pm 8.3 ; Salt+L-NAME:154.9 \pm 8.7 ) compared with control $(94.2 \pm 6.8 ; \mathrm{P}<0.05)$. The MAP was significantly $(\mathrm{P}<0.05)$ higher in the L-NAME group than in all the other groups. The heart rate fell significantly in the salt + L-NAME group compared to control $(\mathrm{P}<0.05)$. The $\mathrm{IC}_{50}$ of acetylcholine in aortic rings from L-NAME rats $\left(7.9 \times 10^{-1} \pm 6.0 \times 10^{-}\right.$ $\left.{ }^{3}\right)$ was significantly higher than in rings from control $\left(9.4 \times 10^{-8} \pm 2.8 \times 10^{-8}\right)$, salt $\left(7.8 \times 10^{-7} \pm 4.7 \times\right.$ $\left.10^{-7}\right)$ and salt + L-NAME $\left(3.3 \times 10^{-7} \pm 2.1 \times 10^{-7}\right)$ rats $(\mathrm{P}<0.05)$. The $\mathrm{IC}_{50}$ of histamine and SNP in the rings from the test groups of rats showed no significant difference from control. These results suggest that the hooded rat may be useful for experimental hypertension studies. Also, endothelium dependent and independent relaxations were preserved in the various forms of hypertension studied except in chronic NOS inhibition where the former was attenuated in response to acetylcholine.
\end{abstract}

Key Words: Experimental hypertension, inbred Hooded (Aguti) rat.

\section{Introduction}

Experimental hypertension models are useful for delineating the mechanisms of hypertension and for developing effective therapies for clinical hypertension (Bohr and Dominiczak, 1991). It has long been recognized that out bred heterogeneous stocks of rats give variable and inconsistent results when testing the effect of nongenetic factors such as salt on blood pressure (Meneely and Ball, 1958). This led Dahl, Heine and Tassinari (1962a) to hypothesize that the variable blood pressure responses to salt in these rats were due to genetic differences. They proved their hypothesis by selective inbreeding during excess dietary salt loading (Dahl, Heine and Tassinari, 1962a and b). They obtained the DS (Dahl Sensitive) strain whose blood pressure rose in response to dietary salt loading and DR (Dahl Resistant) strain whose blood pressure did not. Similarly Okamoto and Aoki (1963) developed the spontaneously hypertensive rat (SHR) by mating two WistarKyoto (WKY) rats with elevated blood pressure followed by selective in breeding of their off springs over several generations. Thus inbred strains, probably because of genetic homozygosity, are essential tools for studying the effect of nongenetic or environmental factors on blood pressure (Bohr and Dominiczak, 1991). Consequently several studies have examined the effects of nongenetic or environmental factors such as salt loading (Dahl, Heine and Tassinari, 1962a and b; Obiefuna et al,1991; Adegunloye and Sofola, 1997; Nicco et al, 2000) and nitric oxide synthesis inhibition (Aisaka et al., 1989; Arnal et al, 1993; Jover et al 1993; Pollock et al., 1993; Hu, Manning and Brands, 1994; Verhagen et al., 1999; da Cunha et al., 2000) on 
inbred rat strains including Dahl, SpragueDawley (SD), Wistar, Sabra and other rat strains. These served as good models of saltsensitivity and endothelial dysfunction respectively.

At our animal house facility at the College of Medicine, University of Lagos, Nigeria, there are inbred colonies of SpragueDawley (SD), Wistar and hooded (Aguti) rats. The inbred hooded (Aguti) rat colony has been maintained since 1962 from a stock brought in by some of the founding faculty from Australia. However these rats are considered unsuitable for research and are accepted grudgingly for students' practical classes. This is because of the erroneous belief that they are a crossbreed between the albino rat and the black domestic rat because of their appearance (Figure 1). We hypothesized that since the hooded rat colony in the animal house had been consistently inbred for almost fifty years, they were likely to be genetically homozygous and therefore likely to be useful for experimental hypertension studies (Meneely and Ball, 1958; Dahl, Heine and Tassinari, 1962a and b; Okamoto and Aoki, 1963; Bohr and Dominiczak, 1991). To test this hypothesis hooded rats were obtained from this inbred colony and subjected to dietary salt loading and/or nitric oxide synthase (NOS) inhibition. Thereafter responses to some vasodilators were studied in order to investigate if the hypertension is associated with a diminution of endothelium dependent and independent relaxations.

\section{Methods}

Animals

Hooded (Aguti) rats (Figure 1) are a strain of rats distinct from the SD or Wistar rat. A stock was originally obtained for the animal house, College of Medicine, University of Lagos, Nigeria by some of the founding faculty from Australia in the early 1960s. An inbred colony has been maintained there since. These rats have black eyes and their tails, ears and feet are of a darker hue than the SD or Wistar rat. They are called hooded rats probably because they appear to be wearing a black/dark brown hood. Hence their faces, heads, necks and upper parts of their bodies up to the fore limbs are covered by the black/dark brown fur. Also a streak of black/dark brown fur courses down the back of the rat usually terminating at the point where the tail joins the body. The rest of the body up to the hind limbs is covered with white fur (Figure 1).

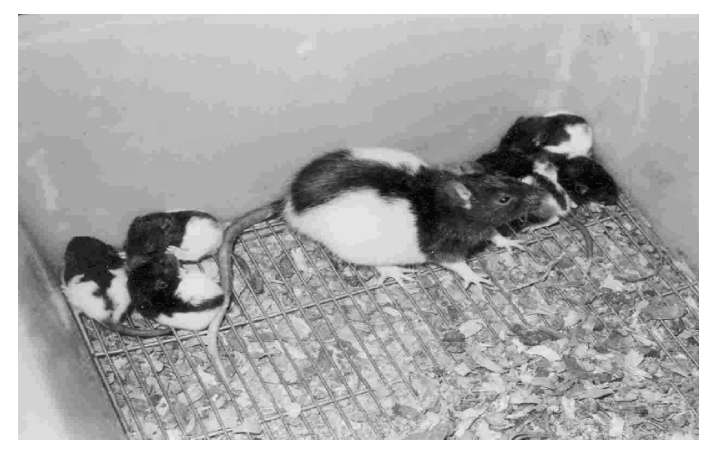

Figure 1. A female hooded (Aguti) rat with her litter.

\section{Experimental Protocol}

In bred male hooded rats aged 8-10, weeks were randomly divided into four experimental groups $(\mathrm{n}=8$ each): control, saltloaded, L-NAME ( ${ }^{\omega}$-L-Arginine Methyl Ester) and salt+L-NAME. Very young (8-10 weeks old) rats were used in this study because it has been shown that younger rats are more sensitive to dietary salt loading than older ones (Dahl et al., 1968; Obiefuna et al., 1991; Sofola et al, 2002). We assumed that this enhanced sensitivity to hypertension might occur in LNAME loading as well.

Control rats were fed a normal rat chow containing $0.3 \% \mathrm{NaCl}$ (Livestock feed, Lagos,
Nigeria). Rats in the salt-loaded group were fed a rat chow containing $8 \%$ salt for 6 weeks (Obiefuna et al, 1991; Adegunloye and Sofola, 1998). Rats in the L-NAME group were fed the normal rat chow and given water containing L-NAME at a dose of 100 $\mathrm{mg} / \mathrm{kg}$ /day for 4 weeks (Pollock et al, 1993). Rats in the salt+L-NAME group were given a rat chow containing $8 \%$ salt for 6 weeks and were given ordinary water in the first two weeks which was later replaced with water containing L-NAME at a dose of 100 $\mathrm{mg} / \mathrm{kg} /$ day in the last four weeks. The rat chow, water and L-NAME solutions were 
available to the appropriate groups of rats ad libitum.

At the end of six weeks, the rats were anaesthetized and their blood pressure and heart rate determined. The rats were anaesthetised using a mixture of $25 \%(\mathrm{w} / \mathrm{v})$ urethane and $1 \%$ $(\mathrm{w} / \mathrm{v})$ alpha-chloralose dissolved in normal saline and injected intraperitoneally at a dose of $5 \mathrm{ml} / \mathrm{kg}$ body weight of the rat (Obiefuna et al, 1991). Following the induction of anaesthesia, the trachea was cannulated to ensure uninterrupted airflow in and out of the lungs. Next, the common carotid artery was cannulated and connected to a pressure transducer (Statham Gould, model P231D, Hato Rey, Pueto Rico) which was in turn coupled to a Grass Polygraph (model 7D; Grass Instruments, Quincy, Mass., USA) for the measurement of blood pressure (Obiefuna et $a l, 1991)$. The mean arterial pressure was measured by electronically damping the pressure pulses (Obiefuna et al, 1991). The heart rate was determined by counting the number of arterial pulses in 15 seconds and then multiplying by 4 to convert to beats/minute (Obiefuna et al, 1991).

\section{Preparation and Mounting of Aortic Rings}

The thoracic cavity was quickly opened and the aorta exposed. It was freed of fat and connective tissues, removed quickly and placed in a Petri dish containing Physiological Salt Solution (PSS). The aortic lumen was gently flushed with PSS and sectioned into $2 \mathrm{~mm}$ ring segments. Each aortic ring was suspended in a $20 \mathrm{ml}$ jacketed tissue bath containing PSS with the following composition (Obiefuna et al, 1991; Adegunloye and Sofola, 1997a) (mmol/l): $\mathrm{NaCl}: 119.0 ; \mathrm{KCl}, 4.7 ; \mathrm{KH}_{2} \mathrm{PO}_{4}, 1.2$; $\mathrm{MgSO}_{4}, 1.2 ; \mathrm{NaHCO}_{3}, 24.9 ; \mathrm{CaCl}_{2}, 1.6$ and glucose, 11.5). The temperature of the bath was maintained at $37^{\circ} \mathrm{C}$ and the solution bubbled with a $95 \% \mathrm{O}_{2} 5 \% \mathrm{CO}_{2}$ gas mixture $(\mathrm{pH} 7.35$ 7.40). Each ring was mounted between a stainless steel hook connected to the base of the bath and a stainless steel rod anchored to a force transducer (FT. O3; Grass Instruments, Quincy, MA, USA) connected to the Grass polygraph for recording of isometric contractions. The ring was placed under a passive tension of $2 \mathrm{~g}$. A 90 minute equilibration period was allowed during which it was stimulated three times with $10^{-7} \mathrm{~mol} / \mathrm{l}$ noradrenaline for 5 minutes at 30 minute intervals (Obiefuna et al.1991; Adegunloye and Sofola, 1997a).

For endothelium-independent relaxation studies, the aortic rings were denuded of endothelium by gently rolling them around a needle placed in their lumen for about 30-60 seconds (Adegunloye and Sofola, 1997a).
Successful endothelial removal was confirmed after mounting, by failure of aortic rings precontracted with $10^{-7} \mathrm{M}$ noradrenaline to relax to $10^{-6} \mathrm{M}$ acetylcholine (Furchgott and Zawadzki, 1980).

\section{Endothelium-Dependent Relaxations}

The aortic rings were precontracted with $10^{-7} \mathrm{M}$ noradrenaline and at the peak of the contraction acetylcholine $\left(10^{-9}\right.$ to $\left.10^{-5} \mathrm{M}\right)$ was added cumulatively (Obiefuna, Sofola and Ebeigbe, 1991). For relaxation studies with histamine the same procedure was followed as with acetylcholine except that histamine was added at concentrations of $10^{-6}$ to $10^{-3} \mathrm{M}$. The drugs were added such that the effect of the previous concentration had become maximal before the next one was added.

\section{Endothelium-Independent Relaxation}

Endothelium-denuded aortic rings were precontracted with $10^{-7} \mathrm{M}$ noradrenaline. At the peak of the contraction, sodium nitroprusside $\left(10^{-9}\right.$ to $\left.10^{-5} \mathrm{M}\right)$ was added cumulatively (Suzuki, Zweifach and Schmid-Schonbein, 1995) as done earlier for acetylcholine.

\section{Drugs}

All the drugs were obtained from Sigma (Poole, Dorset, UK).

\section{Statistical Analyses}

Results are presented as mean \pm SEM (Standard Error of Mean). The concentrations of the agonists that brought about $50 \%$ of the maximal relaxation $\left(\mathrm{IC}_{50}\right)$ were calculated using a programme for logit transformation of the concentration response curves (Obiefuna, Sofola and Ebeigbe, 1991; Obiefuna et al, 1991; Adegunloye and Sofola, 1997a; Adegunloye and Sofola, 1998). Statistical analysis was done using one way Analysis of Variance (ANOVA) followed by a post-hoc students Newman-Keuls test. $\mathrm{P}<0.05$ was taken as statistically significant.

\section{Results}

Blood Pressure and Heart Rate Changes

Presented in Table 1 are the blood pressure and heart rate changes in the various groups of rats. The MAP rose significantly in the test groups compared to control $(\mathrm{P}<0.05)$. The MAP was significantly $(\mathrm{P}<0.05)$ higher in the L-NAME group than in all the other groups. However the difference in blood pressure between the salt and salt + L-NAME groups was not significant. Also the heart rate fell significantly in the salt + L-NAME group compared to control $(\mathrm{P}<0.05)$. 
Table 1: Mean arterial pressure and heart rate of hooded rats given $8 \%$ salt and or $100 \mathrm{mg} / \mathrm{kg} /$ day

$L-N A M E$. Values are mean $\pm S E M ; n=8$ per group.

\begin{tabular}{llllllll}
\hline & Control & Salt & & L-NAME & & $\begin{array}{l}\text { Salt + L- } \\
\text { NAME }\end{array}$ \\
\hline $\begin{array}{l}\text { Mean arterial } \\
\text { pressure }(\mathrm{mm} \mathrm{Hg})\end{array}$ & $94.2 \pm 6.8$ & $148.3 \pm 4.6^{*}$ & 181.7 & \pm & $8.3^{* \dagger}$ & $154.9 \pm 8.7^{*}$ \\
$\begin{array}{l}\text { Heart rate (beats / } \\
\text { inute) }\end{array}$ & $401.6 \pm 9$ & $376.0 \pm 17$ & 431.0 & \pm & 20 & $322.0 \pm 7^{*}$ \\
\hline
\end{tabular}

$* P<0.05$ vs control; $\dagger P<0.05$ vs salt and salt $+L-N A M E$.

Table 2. The $I C_{50}$ of Acetylcholine in endothelium intact aortic rings obtained from hooded rats given $8 \%$ salt and or $100 \mathrm{mg} / \mathrm{kg} /$ day L-NAME.

\begin{tabular}{ll}
\hline \multicolumn{1}{c}{ Group } & Mean \pm SEM (M) \\
\hline Control $(\mathrm{n}=8)$ & $9.4 \times 10^{-8} \pm 2.8 \times 10^{-8 *}$ \\
Salt $(\mathrm{n}=10)$ & $7.8 \times 10^{-7} \pm 4.7 \times 10^{-7 *}$ \\
L-NAME $(\mathrm{n}=10)$ & $7.9 \times 10^{-1} \pm 6.0 \times 10^{-3}$ \\
Salt+L-NAME & $3.3 \times 10^{-7} \pm 2.1 \times 10^{-7 *}$ \\
$(\mathrm{n}=9)$ & \\
\hline
\end{tabular}

$*=P<0.05$ vs L-NAME. $n=$ number of experiments.

Table 3. The $I C_{50}$ of Histamine in endothelium intact aortic rings obtained from hooded rats given $8 \%$ salt and or $100 \mathrm{mg} / \mathrm{kg} /$ day L-NAME.

\begin{tabular}{ll}
\hline \multicolumn{1}{c}{ Group } & Mean \pm SEM $(\mathrm{M})$ \\
\hline Control $(\mathrm{n}=6)$ & $6.4 \times 10^{-5} \pm 2.4 \times 10^{-5}$ \\
Salt $(\mathrm{n}=7)$ & $1.5 \times 10^{-3} \pm 1.4 \times 10^{-3}$ \\
L-NAME $(\mathrm{n}=10)$ & $1.8 \times 10^{-3} \pm 1.5 \times 10^{-3}$ \\
& \\
Salt+L-NAME $(\mathrm{n}=11)$ & $3.2 \times 10^{-5} \pm 1.6 \times 10^{-5}$ \\
\hline
\end{tabular}

$n=$ number of experiments.

Table 4. The $I_{50}$ of Sodium nitroprusside in endothelium denuded aortic rings obtained from hooded rats given $8 \%$ salt and or $100 \mathrm{mg} / \mathrm{kg} /$ day L-NAME.

\begin{tabular}{ll}
\hline \multicolumn{1}{c}{ Group } & Mean \pm SEM $(\mathrm{M})$ \\
\hline Control $\quad(\mathrm{n}=6)$ & $1.0 \times 10^{-8} \pm 3.5 \times 10^{-9}$ \\
alt $(\mathrm{n}=6)$ & $2.8 \times 10^{-8} \pm 1.2 \times 10^{-8}$ \\
L-NAME $(\mathrm{n}=8)$ & $1.1 \times 10^{-8} \pm 1.9 \times 10^{-9}$ \\
Salt+L-NAME $(\mathrm{n}=6)$ & $6.8 \times 10^{-9} \pm 3.1 \times 10^{-9}$ \\
\hline \multicolumn{3}{l}{$n=$ number of experiments. }
\end{tabular}

\section{Endothelium-Dependent Relaxation}

Figure 2 shows the relaxation-response curves to acetylcholine. The L-NAME curve was significantly shifted above the control curve as well as the salt and salt+L-NAME curves $(\mathrm{P}<0.05)$. However the control, salt and salt $+\mathrm{L}-$ NAME curves showed no significant difference from each other. Presented in Table 2 are the $\mathrm{IC}_{50} \mathrm{~s}$ of acetylcholine in aortic rings from the 4 groups of rats. The $\mathrm{IC}_{50}$ of acetylcholine in $\mathrm{L}$ NAME rings was significantly higher than in control, salt and salt+L-NAME groups $(\mathrm{P}<0.05)$.

\section{Relaxation-Response to Histamine}

The relaxation response curves to histamine in endothelium intact rings showed no significant difference from one another (Figure 3). Also the $\mathrm{IC}_{50} \mathrm{~s}$ were not significantly different from each other (Table 3).

\section{Endothelium-Independent Relaxation}

The relaxation response curves to sodium nitroprusside in endothelium denuded rings did not differ significantly from each other (Figure 4). Also the $I C_{50} s$ showed no significant difference in the different groups (Table 4). 


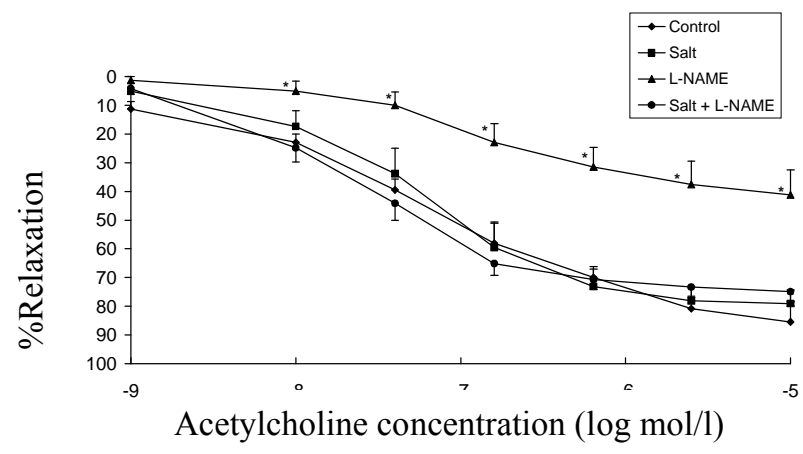

Figure 2. Endothelium-dependent Relaxation: Relaxation response to acetylcholine.

Line graphs showing concentration response to acetylcholine in endothelium intact aortic rings obtained from control rats and those given salt and or L-NAME. *P < 0.05 vs control, salt and salt + L-NAME. $n$ for each point ranges from 8-10 observations.

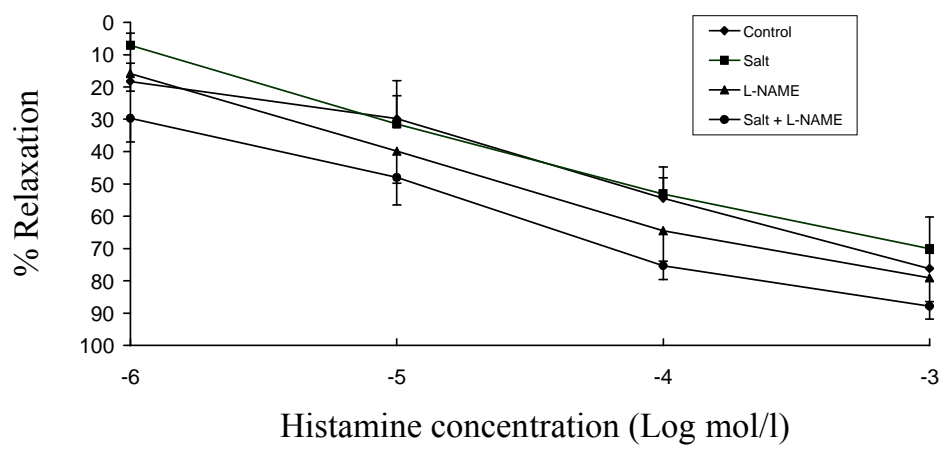

Figure 3. Endothelium-dependent Relaxation: Relaxation-response to histamine.

Line graphs showing concentration response to histamine in endothelium intact aortic rings obtained from control rats and those given salt and or L-NAME. $n$ for each point ranges from 6-11 observations.

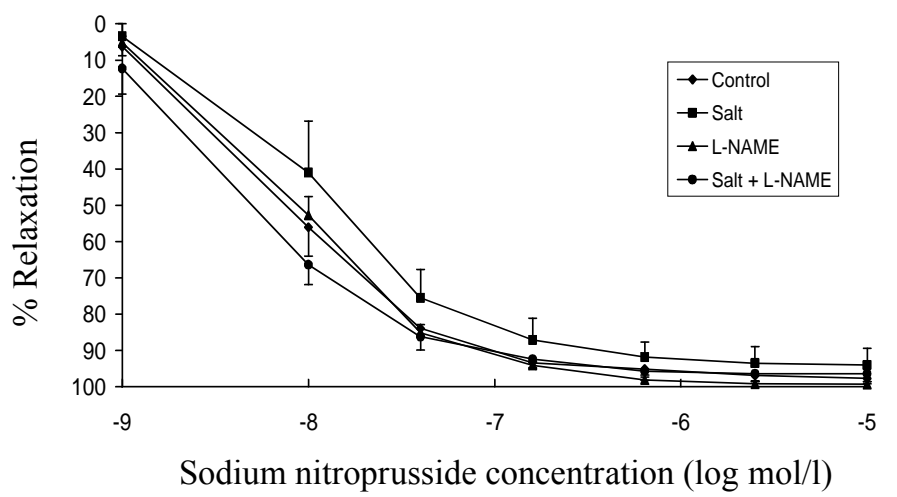

Figure 4. Endothelium-Independent Relaxation: Relaxation Response to sodium nitroprusside. Line graphs showing concentration response to sodium nitroprusside in endothelium-denuded aortic rings obtained from control rats and those given salt and or L-NAME. $n$ for each point ranges from 6-8 observations. 


\section{Discussion}

The major new finding in this study is that inbred hooded (Aguti) rats became hypertensive following the administration of excess dietary salt and/or L-NAME. It also confirms the notion that genetic homozygousity of inbred strains makes them useful for the study of nongenetic/environmental factors (Meneely and Ball, 1958; Dahl, Heine and Tassinari, 1962a; Bohr and Dominiczak, 1991) such as salt or LNAME. Also aortic rings obtained from the hypertensive and control hooded rats in this study responded to the classical endothelium dependent and independent vasodilators in a comparable manner to previous studies in other rat strains. These findings suggest the suitability of the hooded rat for experimental hypertension studies.

Salt loading and L-NAME loading were done for 6 and 4 weeks respectively because earlier reports suggest that hypertension was fully developed at these periods (Obiefuna et al., 1991; Pollock et al, 1993; Adegunloye and Sofola, 1998).

L-NAME which inhibits NO in the endothelium had the greatest effect on blood pressure demonstrating the role of $\mathrm{NO}$ as a potent vasodilator (Moncada and Higgs 1993). L-NAME, like other analogues of L-Arginine, is a potent vasoconstrictor that produces a hypertensive response by blocking the NO vasodilator tone (Arnal et al, 1993; Pollock et al., 1993; da Cunha et al., 2000). The blood pressure in the L-NAME group was significantly higher than in salt loaded and salt+L-NAME rats. No additive effect of salt and L-NAME on blood pressure was found in this study. Rather the blood pressure remained similar in the salt-loaded and salt+L-NAME groups. The lack of an additive effect suggests that both salt loading and L-NAME may share a common mechanism(s) for elevating blood pressure. Alternatively, part of the mechanism underlying the effect of salt may be interfering with the mechanism by which L-NAME produces its vascular effects. An earlier study in which L-NAME and salt were combined to induce hypertension in the dog (Manning and $\mathrm{Hu}, 1994)$ did not find an additive effect thereby agreeing with the findings of the present study. The lack of change in heart rate in salt loaded hooded rats compared to control observed in this study has also been reported in Wistar (Nwaigwe and Sofola, 1989) and SD (Obiefuna et al., 1991; Adegunloye and Sofola, 1997b) rats.

The relaxation response to acetylcholine was significantly reduced and the $\mathrm{IC}_{50}$ significantly increased in aortic rings from LNAME rats compared to those from control, salt and salt+L-NAME animals. This suggests that endothelium dependent relaxation to acetylcholine was inhibited in the L-NAME rats compared to the other groups. Thus the hypertension in the L-NAME rats may be associated with this. However the L-NAME curve tended to fall with increasing concentration of acetylcholine suggesting some relaxation (Fig. 2). An L-NAME dose of $100 \mathrm{mg} / \mathrm{kg} /$ day was used in the present study because it has been reported that at this dose NOS (Nitric Oxide Synthase) inhibition is optimal in Wistar (Arnal, Warin and Michel, 1992) and SD (Pollock et al, 1993) rats. The slight relaxation observed in this study at this dose could therefore be a peculiarity of the hooded rat or it could be that this dose may not be optimal in this strain. It is tempting to also speculate that this observation may be due the release of the endothelium dependent hyperpolarizing factor (EDHF) in response to acetylcholine. However previous works in other rat strains have observed a relaxant action of EDHF in only resistance arteries (Feletou and Vanhoutte, 1988; Ebeigbe et al, 1990; Adeagbo and Triggle, 1993; Sofola et al, 2002) and not in conduit arteries like the aorta. However, it may be worthwhile to test this hypothesis in the hooded rat.

In this study acetylcholine-induced relaxation was similar in aortic rings from salt loaded and salt+L-NAME rats as well as in the control (Figure 2) suggesting that endothelium dependent relaxation to acetylcholine was preserved in them in spite of the hypertension. This finding is in accord with earlier findings in salt induced hypertension in SD rat (Obiefuna et al, 1991; Adegunloye and Sofola, 1997b; Sofola et al, 2002). A similar finding has also been reported in the SHR and SHRSP compared to their normotensive WKY counterparts (Sim and Chua, 1985; Lee and Webb, 1992). However there are reports that suggest that endothelium dependent relaxation to acetylcholine is reduced in SHR (Suzuki, Zweifach and SchmidSchonbein, 1995), renal hypertension (Van de Voorde and Leusen, 1986) and DOCA salt hypertension (Van de Voorde and Leusen, 1986).

Neither the relaxation response curves to histamine nor the $\mathrm{IC}_{50} \mathrm{~S}$ differed in the test groups compared to control. This suggests that endothelium dependent relaxation to histamine was preserved. Thus the hypertension in the rats may not be associated with an attenuated endothelium dependent response to histamine. Thus NO release through histamine-receptor stimulation may be regarded as normal in these rats in spite of the hypertension. This finding is at variance with earlier reports from this 
laboratory in salt loaded SD rats (Obiefuna, Sofola and Ebeigbe, 1991; Adegunloye and Sofola, 1997a). This disparity may be due differences in rat strain.

Endothelium independent relaxation to sodium nitroprusside (SNP) was not different either within the test groups or when compared to control. SNP is a nitric oxide (NO) donor (Moncada and Higgs, 1993) and an activator of vascular smooth muscle (VSM) soluble guanylate cyclase (Chang, Zhong and Davis, 1996) leading to the production of cyclic guanosine monophoshphate (cGMP) that induces relaxation. Thus this finding suggests that the reactivity or responsiveness of the vascular smooth muscle to $\mathrm{NO}$ in these forms of hypertension in the hooded rat is preserved. This is in accord with earlier findings in renovascular hypertension (Van de Voorde and Leusen, 1986), SHR (Suzuki, Zweifach and Schmid-Schonbein, 1995), DOCA salt (Van de Voorde and Leusen, 1986) and salt sensitive hypertension in Dahl (Boegehold, 1992) and SD (Sofola et al, 2002) rats.

Our results suggest that L-NAME hypertension in the hooded rat may be due in part to an attenuated endothelium dependent relaxation. However both endotheliumdependent and independent relaxations were preserved in salt-induced hypertension and salt+L-NAME hypertension in the hooded rat suggesting that other mechanisms may be responsible for the elevated blood pressure. These mechanisms may include enhanced contractile responses to endogenous vasoconstrictors such as noradrenalin or attenuated responses to other vasodilator systems such as the kallikrein-kinin system and atrial natriuretic peptide. The relaxant effect of acetylcholine observed in this study in aortic rings from hooded rats having a supposedly optimal dose of L-NAME (Pollock et al, 1993; Arnal, Warin and Michel, 1992) may deserve further investigation.

In summary, hypertension has been successfully induced in inbred hooded (Aguti) rats by dietary salt and/or L-NAME loading. Also, endothelium dependent and independent relaxations were preserved in the various forms of hypertension studied except in chronic NOS inhibition where the former was attenuated in response to acetylcholine. It is concluded that the hooded rat may be useful for experimental hypertension studies.

\section{Acknowledgements}

Many thanks to the Usman Danfodio University Sokoto, Nigeria, for awarding a study fellowship to Frank B.O. Mojiminiyi. This work was supported by a University of Lagos research grant to Professor O.A. Sofola.

\section{References}

Adeagbo, A. S. and Triggle, C. R. (1993). Varying extracellular $\left[\mathrm{K}^{+}\right]$: a functional approach to separating EDHF and EDNOrelated mechanisms in perfused rat mesenteric arterial bed. J. Cardiovasc. Pharmacol. 21, 423-429.

Adegunloye, B. J. and Sofola, O. A. (1997a). Effect of dietary salt loading and high calcium diet on vascular smooth muscle responses and endothelium function in rats. Clin. Exp. Pharm. Physiol. 24, 814-818.

Adegunloye, B. J. and Sofola, O. A. (1997b). High dietary calcium attenuates the enhanced vasoconstictor effects of serum from salt-loaded rats. Afr. J. Med. med. Sci. $26,47-50$.

Adegunloye, B. J. and Sofola, O. A. (1998). Relaxation responses of aortic rings from salt loaded high calcium fed rats to potassium chloride, calcium chloride and magnesium sulphate. Pathophysiology 4, 275-280.

Aisaka, K., Gross, S. S., Griffith, O. W. and Levi, R. (1989). $\mathrm{N}^{\mathrm{G}}$-methyl-arginine, an inhibitor of endothelium-derived nitric oxide synthesis is a potent pressor agent in the guinea pig: Does nitric oxide regulate blood pressure in vivo? Biochem. Biophys. Res. Commun. 160, 881-886.

Arnal, J. F., E 1 Amrani, A. I., Chatellier, G., Menard, J. and Michel, J. B. (1993). Cardiac weight in hypertension induced by nitric oxide synthase blockade. Hypertension. 22, 380-387

Arnal, J. F, Warin L, Michel J. B. (1992). Determinants of aortic cyclic guanosine monophosphate in hypertension induced by chronic inhibition of nitric oxide synthase. J. Clin. Invest. 90, 647-652

Boegehold, M. A. (1992). Reduced influence of nitric oxide on arteriolar tone in hypertensive Dahl rats. Hypertension. 19, 290-95

Bohr, D. F. and Dominiczak, A. F. (1991) Experimental Hypertension. Hypertension. 17(1 Suppl), I39-I44.

Chang, K. S. K., Zhong, M. Z. and Davis R. F. (1996). Indigo carmine inhibits endothelium-dependent and independent vasodilation. Hypertension. 27, 228-34

da Cunha, V., Rossoni, L. V., Oliviera, P. A., Poton, S., Pretti, S.C., Vassallo, D. V. and Stefanon, I. (2000). Cyclooxygenase inhibition reduces blood pressure elevation and vascular reactivity dysfunction caused 
by inhibition of nitric oxide synthase in rats. Clin. Exp. Hypertens. 22, 203-215.

Dahl, L. K., Heine, M. and Tassinari, L. (1962a). Role of genetic factors in susceptibility to experimental hypertension due to chronic excess salt ingestion. Nature. 194, 480-82.

Dahl, L. K., Heine, M. and Tassinari, L. (1962b). Effects of chronic excess salt ingestion. Evidence that genetic factors play an important role in susceptibility to experimental hypertension. J. Exp. Med. 115, 1173-1190.

Dahl, L. K., Knudsen, K. D., Heine, M. A. and Leitl, G. J. (1968). Effects of Chronic excess salt ingestion. Modification of experimental hypertension in the rat by variations in the diet. Circ. Res. 22,11-18.

Ebeigbe, A. B., Cressier, F., Kunneh, M. K., Luu, T. D. and Criscione, L. (1990). Influence of NA-monomethyl L-arginine on endothelium-dependent relaxation in the perfused mesenteric vascular bed of the rat. Biochem. Biophysic. Res. Commun. 169, 873-879.

Feletou, M. and Vanhoutte, P. M. (1988). Endothelium-dependent hyperpolarization of canine coronary smooth muscle. $\mathrm{Br}$. J. Pharmacol. 93, 515-24.

Furchgott, R. F. and Zawadzki, J. V. (1980). The obligatory role of endothelial cells in the relaxation of arterial smooth muscle by acetylcholine. Nature 288, 373-376.

$\mathrm{Hu}$, L., Manning, R. D. Jr. and Brands, M. W. (1994). Long term cardiovascular role of nitric oxide in conscious rats. Hypertension. 23, 185-194.

Jover, B., Herizi, A., Ventre, F., Dupont, M. and Mimran, A. (1993). Sodium and angiotensin in hypertension induced by long-term nitric oxide blockade. Hypertension. 21, 944-948.

Lee, L. and Webb, R. C. (1992). Endotheliumdependent relaxation and $\mathrm{L}$ arginine metabolism in genetic hypertension. Hypertension. 19, 435-41.

Manning, R. D. Jr. and Hu, L. (1994). Nitric oxide regulates renal hemodynamics and urinary sodium excretion in dogs. Hypertension. 23, 619-625.

Meneely, G. R. and Ball, C. O. T. (1958). Experimental epidemiology of chronic sodium chloride toxicity and the protective effect of potassium chloride. Am. J. Med. 25, 713-725

Moncada, S. and Higgs, A. The L-Arginine Nitric Oxide Pathway. (1993). N. Engl. J. Med. 329, 2002-2012.
Nicco, C., Martin, H., Yagil, C., Yagil, Y., Bankir, L. and Boneby, N. (2000). Regulation of sodium intake of type I angiotensin II mRNAs in the kidney of Sabra rats. J. Hypertens. 18, 1097-1105.

Nwaigwe, C. I. and Sofola, O. A. (1989). Potassium but not nifedipine reduces hypertension in anaesthetized salt-loaded rats. Med. Sci. Res. 17, 767-68.

Obiefuna, P. C. M., Ebeigbe, A. B., Sofola, O. A. and Aloamaka, C. P. (1991). Altered responses of aortic smooth muscle from Sprague-Dawley rats with salt-induced hypertension. Clin. Exp. Pharm. Physiol. 18, 813-818.

Obiefuna, P. C. M., Sofola, O. A. and Ebeigbe, A. B. (1991). Dietary salt loading attenuates endothelium-dependent relaxation in response to histamine but not to acetylcholine in rat aortic rings. Exp. Physiol. 76, 135-138.

Okamoto, K. and Aoki, K. (1963). Development of a strain of spontaneously hypertensive rats. Jpn. Circ. Jr. 27, 282293

Pollock, D. M., Polakowski, J. S., Divish, B. J. and Opgenorth, T. J. (1993). Angiotensin blockade reverses hypertension during long term nitric oxide synthase inhibition. Hypertension. $21,660-666$.

Sim, M. K and Chua, M. E. (1985). Altered responsivensess of the aorta of hypertensive rats to histamine and acetylcholine. Jap. J. Pharmac. 39, 395-97.

Sofola, O. A., Knill, A., Hainsworth, R. and Drinkhill, M. (2002). Change in endothelial function in mesenteric arteries of SpragueDawley rats fed a high salt diet. J. Physiol. 543, 255-260.

Suzuki, H., Zweifach, B. W. and SchmidSchonbein, G. W. (1995). Vasodilator response of mesenteric arterioles to histamine in spontaneously hypertensive rats. Hypertension 26, 397-400.

Van de Voorde, J. and Leusen, I. (1986). Endothelium-dependent and independent relaxation of aortic rings from hypertensive rats. Am. J. Physiol. 250, H711-H717

Verhagen, A. M. G., Braam, B., Boer, P., Grone, H. J., Koomans, H. A. and Joles, J. A. (1999). Losartan-sensitive renal damage caused by chronic NOS inhibition does not involve increased renal angiotensin II concentrations. Kidney Int. 56,222-231

Received: $1 / 6 / 2007$

Accepted: 25/11/2007 